\title{
Nuestro primer número
}

Desde el 16 de diciembre de 2013, el Grupo de Estudios Históricos sobre la Guerra (GEHiGue) del Instituto Ravignani de la Facultad de Filosofía y Letras de la Universidad de Buenos Aires, unidad ejecutora UBA/CONICET, viene desarrollando una constante actividad de investigación y de intercambio académico con especialistas de la Argentina y del exterior en torno al estudio de la problemática bélica desde una perspectiva histórica. Como resultado, se ha conformado en el ámbito universitario argentino un espacio de investigación y de debate intelectual acerca de la guerra, concebida como un fenómeno netamente social, que, además de su faceta militar, comprende otras dimensiones de análisis. Esta mirada integradora de la guerra incorpora en consecuencia a combatientes y a civiles, a beligerantes y a neutrales, dando cuenta de la omnipresencia de los conflictos armados en la sociedad moderna.

Historia \& Guerra nace como una iniciativa destinada a coronar la labor emprendida por el GEHiGue en diálogo con investigadores de diferentes latitudes y a poner a disposición de sus lectores nuevas investigaciones que aporten al conocimiento renovado de la guerra desde variadas perspectivas historiográficas. Sus páginas están abiertas a colaboraciones de índole empírica o teórico-metodológica que se ocupen de guerras y conflictos desarrollados desde los inicios del "siglo XIX largo" (en palabras de Eric Hobsbawm) hasta la actualidad. El rango espacial de los trabajos incluye diversas escalas de análisis, desde estudios de caso locales hasta otros transnacionales, si bien los referidos a América Latina y Argentina son particularmente bienvenidos.

Este primer número reúne cuatro artículos de investigación sobre un área de estudios en plena expansión: la historia social y cultural de la Primera Guerra Mundial. En las últimas décadas y especialmente en el marco del centenario del conflicto, esta corriente historiográfica ha mostrado un notable dinamismo, que redundó en un creciente interés en las experiencias y en las representaciones de la guerra de diferentes actores sociales, individuales o colectivos. Asimismo, los historiadores han comenzado a interesarse por el estudio de las repercusiones de esta guerra global en regiones habitualmente marginadas de la historiografía sobre la Gran Guerra, por lo general centrada en el teatro bélico europeo y en los principales beligerantes. Así, aunque de manera aún incipiente, los impactos del conflicto en América Latina han comenzado a 
concitar la atención de los historiadores. Tres de los trabajos de este número analizan diversas aristas de esos impactos en Brasil. Luciana Fagundes traza un balance historiográfico sobre las repercusiones culturales del conflicto en esa nación. Livia Claro se interesa por una fracción específica de la polarizada opinión pública brasileña: los admiradores de la Alemania imperial. Por su parte, Fernanda Arouca analiza la política de censura implementada por el Estado brasileño tras su entrada en la guerra en 1917.

Dentro de los estudios socioculturales acerca de la Gran Guerra, la exploración de la memoria del conflicto se ha mostrado como un área muy fértil. En su artículo, Norman Fraser Brown examina la memoria colectiva de la Gran Guerra presente en un batallón de infantería escocés paradigmático: el Black Watch.

La sección de artículos se completa con un trabajo referido a la guerra civil española. Gonzalo Berger Mulattieri nos acerca a dos cuestiones centrales que debió encarar el bando republicano (el financiamiento y el armamento), centrándose en el caso de las milicias antifascistas catalanas.

Por su parte, las reseñas nos acercan a tres libros recientes sobre temas y enfoques variados relacionados con la guerra: la historia medioambiental de la guerra civil norteamericana, la historia global de la Gran Guerra a través de la lente de los mediadores culturales y la organización de los servicios secretos alemanes durante la guerra fría.

La publicación de una revista académica es un proceso arduo, complejo y desafiante, que requiere de la colaboración de diversas instituciones e individuos. Quiero expresar mi reconocimiento a las autoridades del Instituto Ravignani por su respaldo a esta iniciativa y a la Subsecretaría de Publicaciones de la Facultad de Filosofía y Letras de la Universidad de Buenos Aires por su asesoramiento, cooperación y disposición para que este primer número de Historia \& Guerra pueda ver la luz. Agradezco asimismo a los integrantes del comité editorial por su compromiso y dedicación incansables, y a los miembros del comité consultivo por prestigiarnos con su participación. Asimismo, hago extensiva mi gratitud a los autores que confiaron en nosotros para publicar sus trabajos y a los evaluadores que, con su rigurosidad y profesionalismo, garantizaron la calidad y la seriedad académica de la revista. Historia \& Guerra se ha hecho realidad gracias al concurso de todos ellos.

María Inés Tato

Directora 